\section{Buchrezension zu:} Organische Chemie

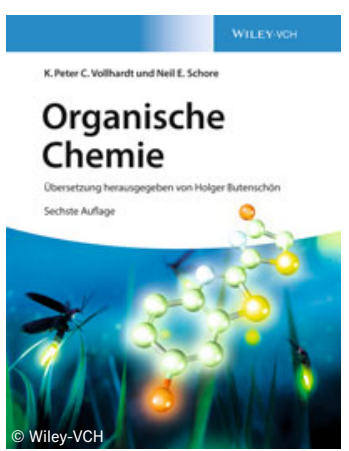

Organische Chemie

K. P. C. Vollhardt und Neil E. Schore

Übersetzung herausgeg. von Holger Butenschön,

1592 S., Wiley-VCH, 6. Aufl., 2020. $H C, 89,90 €$.

ISBN: 9783527345823

Auch als e-Book erhältlich

DOI: 10.1007/s12268-021-1521-9

(c) Springer-Verlag GmbH 2021

1.600 Seiten Organische Chemie! Die vorliegende 6. deutsche Auflage ist eine Übersetzung der 2018 erschienenen 8. amerikanischen Auflage: ein wahrhaft umfassendes aktuelles Werk, didaktisch ausgereift und etabliert bei Studierenden und Unterrichtenden der Organischen Chemie!

Die Chemie ist eine dynamische Wissenschaft. Auch ein Lehrbuchklassiker erfordert daher immer neue Auflagen. Auch der ,neue' Vollhardt enthält Neues: Jedem Kapitel wurde eine kurze Darstellung des Lernziels vorangestellt. Übersichtliche Zusammenfassungen beenden die einzelnen Abschnitte und am Kapitelende wird die Einordnung der Inhalte in den Gesamtzusammenhang der Chemie durch eine Rubrik „Im Überblick“ sichergestellt. Schwerpunkte sind wie bereits in früheren Auflagen „Verständnisübungen“. Im Vorwort heben die Autoren besonders den Kontext mit der Praxis hervor, wie z. B. der Material- und medizinischen Wissenschaft. Dieser scheint jedoch eher kurz und zufällig selektiv zu sein, bedingt durch die Gegebenheiten des möglichen Umfangs eines Grundlehrbuchs.
Das Werk erscheint auch als e-Book (das dem Rezensenten nicht vorlag). Das mag der Grund sein, warum in der Print-Edition jeglicher Link zum Internet fehlt. Das Internet sollte Grundlage für alles Lehren und Lernen sein, stellt es doch sicher, auch die letzten Neuerungen einzubeziehen. Es würde gerade in Bezug auf praktische Anwendungen den Nutzen des Werkes wesentlich erweitern. Beispiel: Die ,negativen' Effekte der FCKWs werden in der Printversion dargestellt, nicht aber die von Organophosphaten und anderen synthetischen Pestiziden und Toxinen. (Neugierig und zur Abschätzung der Aktualität des Lehrbuchs stellte der Rezensent an das recht knappe Stichwortverzeichnis am Ende des Buches die Frage: Was ist Tabun, Sarin, was Novitschok? Keine Antwort ...)

Trotz allem: Der Chemiestudent braucht ein Lehrbuch für jede Disziplin seines Fachs, das inn durch sein Studium begleitet, in dem er sich auskennt. Der Vollhardt könnte so ein Begleiter sein!

Ferdinand Hucho, Berlin,

hucho@chemie.fu-berlin.de 